\title{
Estratégias em promoção aos objetivos de desenvolvimento sustentável: Experiências com a reprodução de tecnologias sociais no Brasil
}

\author{
Strategies to promote sustainable develop,ent goals: Experiences with the \\ reproduction of social technologies in Brasil
Yasmin Dal Lago Nachtigall', Mariana da Silva Viola", Gabriel Eduardo Gonçalves"', Sibele Vasconcelos de OliveiralV

\begin{abstract}
Resumo:
A pobreza, o desemprego e as desigualdades têm sido problemas socioeconômicos perseguidos pelas agências públicas e privadas em promoção ao desenvolvimento sustentável. Para alcance aos ODS, a Agenda 2030 definiu planos de ação com vistas a articular esforços para que a qualidade de vida e o bem-estar social possam ser percebidos nas diferentes regiões do globo. No Brasil, muitas iniciativas inclusivas de geração de trabalho e renda fazem uso das tecnologias sociais. Sendo assim, o presente estudo visa analisar as especificidades da elaboração e aplicação das tecnologias sociais, bem como avaliar algumas experiências no tocante ao combate às vulnerabilidades socioeconômicas. Observou-se que nos últimos anos, muitos movimentos institucionais e coletivos foram implementados com vistas ao desenvolvimento. A constituição de comissões nacionais e regionais para acompanhar a implementação dos ODS são exemplos passíveis de serem citados. Ainda, a criação da RTS, bem como a aplicação de tecnologias sociais nas diferentes regiões do Brasil (Banco de Palmas, RICS, PAIS, dentre outras) dão conta de exemplificar os processos e conhecimentos que vêm sendo implantados com o objetivo de atendimento à Agenda 2030.
\end{abstract}

Palavras-chave: Desenvolvimento humano; Economia popular; Inclusão social; Nações unidas

\begin{abstract}
:
The poverty, unemployment and social inequalities have been socio economics issues that public and private agencies have pursued in promoting sustainable development. To achieve the SDG, the 2030 Agenda has determined action plans with sights to articulating efforts so the life quality and the social welfare can be perceived in different regions of the globe. In Brazil, many inclusive initiatives in work and income generation make use of social technologies. Therefore, the present study seeks to analyse the specificities of the elaboration and application of social technologies, as well as assess some combating experiences in socioeconomics vulnerabilities. It was observed that in recent years, many institucional and collective movements have been implemented seeking development. The establishment of national and regional committees to monitor the implementation of the SDGs are examples to be cited. Moreover, the creation of RTS, as well as the social technologies application in different regions of Brazil (Banco de Palmas, RICS, PAIS, among others) can exemplify the processes and acquirements that have been implemented to meet the 2030 Agenda.
\end{abstract}

Keywords: Human development; Popular economy; Social inclusion; United nations

\footnotetext{
IAcadêmica do curso de Ciências Econômicas UFSM - yasminnachtigall@hotmail.com

II Acadêmica do curso de Ciências Econômicas UFSM - violamari29@gmail.com

IIIAcadêmico do curso de Ciências Econômicas UFSM - gabo.eduardo88@gmail.com

${ }^{\text {IV }}$ Professora no Departamento de Economia e Relações Internacionais da UFSM - sibele_deoliveira@hotmail.com
} 


\section{Introdução}

As especificidades do desenvolvimento do capitalismo impuseram externalidades socioeconômicas importantes à sociedade, cujas implicações são percebidas quando são avaliados os comportamentos de fenômenos como a pobreza, a miséria e as desigualdades. A despeito do crescimento da integração dos mercados e do comércio global, o capitalismo também é responsável pela precarização dos empregos, pela intensificação das vulnerabilidades e pela exclusão social (DUPAS, 1998).

Desde a década de 1980, o processo de internacionalização das economias capitalistas vem revelando as cruéis faces da égide do grande capital, do individualismo e da competição (SINGER, 2004). A concentração dos meios de produção e as virtudes concorrenciais de mercado reforçam as desigualdades já existentes e instituem dificuldades para a promoção do desenvolvimento humano sustentável.

Buss (2007) ilustrou que, apesar do crescimento da renda e riqueza no mundo, mais de 1,2 bilhões de pessoas viviam em situação de extrema pobreza no início dos anos 2000. As condições para reprodução socioeconômica eram ainda mais severas em regiões historicamente reprimidas, como na África Subsaariana, onde cerca da metade dos habitantes viviam com menos de 1 dólar por dia. No início do século XXI, 222 milhões de habitantes da América Latina e Caribe eram pobres e 18,6\% indigentes (BUSS, 2007).

Mais recentemente, a Comissão Econômica para a América Latina e o Caribe (CEPAL, 2018) ratificou que a erradicação da pobreza e a redução das iniquidades continuam sendo desafios para os países da América Latina. O relatório intitulado "Panorama Social da América Latina" revela que a região permanece sendo a mais desigual do mundo, mesmo diante dos avanços dos últimos 15 anos. Dentre os consequentes dos elevados níveis de desigualdade, cita-se: o subdesenvolvimento, a redução da cidadania e do exercício dos direitos civis, a fragilização da governabilidade democrática, entre outros (CEPAL, 2018).

Sensíveis aos obstáculos históricos e estruturais ao desenvolvimento, os Estados membros da Organização das Nações Unidas lançaram a Agenda 2030. Publicado em 2015, o manifesto prevê um plano de ações para combater os principais problemas e gargalos das sociedades contemporâneas, a incluir o enfrentamento à fome, à miséria, às discriminações e às injustiças sociais.

Nesta oportunidade, foram definidos os Objetivos de Desenvolvimento Sustentável (ODS), que representam o eixo central da Agenda 2030 e que orientam as ações nas três dimensões do desenvolvimento sustentável, a saber, as dimensões econômica, social e ambiental (IPEA, 2018). Os esforços de mobilização institucional contemplam tanto a atuação de entidades públicas (por meio de políticas e programas sociais) quanto por entidades privadas (por meio de projetos individuais e/ou locais).

Destarte, é mister avaliar as contribuições das tecnologias sociais para o atendimento da Agenda 2030. Ao longo dos últimos anos, o Brasil experienciou diversas iniciativas em economia popular, economia criativa e economia solidária, que o permitiram galgar importantes resultados pró-desenvolvimento sustentável. Sobretudo, a análise de suas particularidades pode subsidiar o planejamento de ação articulada, de forma a potencializar os benefícios da inversão de recursos (materiais e imateriais) nos territórios prioritários, nas regiões em vulnerabilidade e acometidas por pobreza extrema.

A redação do presente estudo está organizada em cinco seções, além desta breve introdução. A seguir, discorre-se sobre as ações e estratégias em desenvolvimento humano sustentável. $\mathrm{Na}$ seção 3, são apresentados os processos correlatos à mobilização para o atendimento à Agenda 2030 no Brasil. Por conseguinte, avaliam-se as particularidades das tecnologias sociais reproduzidas no país. Por fim, apresentam-se as conclusões da pesquisa e as referências bibliográficas.

\section{Ações e estratégias em desenvolvimento humano sustentável}

A abordagem acerca do desenvolvimento humano foi modificada ao longo do tempo, perpassando um tratamento puramente econômico do fenômeno social - correlato à avaliação da riqueza e renda - para uma análise que prioriza as liberdades e oportunidades dos indivíduos. Contudo, durante muito tempo, entendeu-se que o termo "desenvolvimento" era análogo ao crescimento econômico. Embora as definições estejam bastante próximas, muitas perspectivas teóricas argumentavam que bastava o aumento na geração de capital para que a economia encontrasse condições para o crescimento e superação de vulnerabilidades.

Para o economista Amartya Sen (1999), vencedor do nobel de economia do ano de 1998, é inapropriado conceber que o objetivo central do ser humano seja maximização da renda ou da riqueza. Nas palavras do renomado autor, "o desenvolvimento tem de estar relacionado sobretudo com a melhora da vida que levamos e das liberdades que desfrutamos" (SEN, 1999, p. 29). Neste cenário, há a possibilidade de englobar elementos plurais e multidimensionais à avaliação do desenvolvimento, a fim de realizarmos representações mais fidedignas à realidade individual e social. 
Sendo assim, na atualidade, segundo Richard Jolly (2003), muitos estudos sobre desenvolvimento humano utilizam da definição atribuída a Amartya Sen e seus precursores para fazer referência ao fenômeno. A mesma perspectiva é utilizada pelo Programa das Nações Unidas para o Desenvolvimento (PNUD), que explora as definições de funcionamentos e capacitações para operacionalizar estimativas em qualidade de vida e desenvolvimento humano. Destarte, o desenvolvimento é interpretado como a evolução e ampliação das escolhas dos indivíduos para que estes possuam liberdades e oportunidades para serem aquilo que desejam (SEN, 1999).

Cabe destacar que o Programa das Nações Unidas para o Desenvolvimento (PNUD) é uma agência da Organização das Nações Unidas (ONU), que atua com o objetivo de erradicação da pobreza e ampliação do bem-estar social. Sendo assim, possui como finalidade a promoção do desenvolvimento humano. Fundado em 1965, encontra-se presente em 166 países.

Através do desenvolvimento e implementação de projetos de cooperação técnica em parcerias com instituições nacionais, o PNUD Brasil visa apoiar: implementação de políticas para fortalecer setores críticos para o desenvolvimento humano; promoção dos Objetivos do Desenvolvimento do Milênio; desenvolvimento de capacidades institucionais nos governos federal, estaduais e municipais; e fortalecimento do papel da sociedade civil e do setor privado na busca do desenvolvimento humano e sustentável (ONU, 2019, p. 1).

Tendo em vista os objetivos institucionais, o PNUD procura estimular a construção de uma vida digna para as pessoas, por meio de associações com a iniciativa privada, governos e sociedade civil. Dentre as ações-foco, citam-se a promoção da igualdade de raça e de gênero, juntamente com a proteção dos direitos humanos. De acordo com dados oficiais do United Nations Development Programme, atualmente, a entidade possui 4.086 projetos realizados pelo mundo, cujas linhas de atuação englobam a erradicação da pobreza, mudanças estruturais e promoção de resiliência perante crises.

Ademais, desde o ano de 1990, o PNUD publica a série de Relatórios do Desenvolvimento Humano, que propõem-se a analisar o desenvolvimento em face global, juntamente com estudos regionais para cada país. Nos documentos publicados periodicamente, é possível perceber a tese de que a riqueza deixa de ser um fim - e passa a ser um meio - para atingir melhores condições de vida para a população. Assim sendo, o desenvolvimento é interpretado como um fenômeno que vai além da natureza econômica (PNUD, 2019).

Ainda em 1990, o PNUD apresentou uma proposta para análise e mensuração do desenvolvimento. Com base nas contribuições teórico-metodológicas dos economistas Mahbub Ul Haq e Amartya Sen, foi possível a criação do Índice de Desenvolvimento Humano (IDH) (PNUD, 2019). O IDH contrapõem a análise puramente econômica realizada pela utilização do Produto Interno Bruto (PIB) como principal proxy do desenvolvimento.

Na concepção do PNUD (2018), ao avaliar apenas o crescimento econômico mediante a observação do PIB, as instituições e países menosprezavam problemas sociais importantes, como a má distribuição da renda. Neste sentido, omitem-se situações particulares, como a de regiões em que há um alto nível de riqueza, em contrapartida, a maior parte de seus integrantes pode vivenciar níveis de pobreza expressivos. De fato, a concentração de renda e riqueza é uma das principais mazelas do sistema capitalista.

Mesmo que o fator financeiro condicione o status de condição de vida da população, o IDH possibilita uma medida mais fidedigna da realidade social ao levar em conta aspectos multidimensionais e que podem ser comparados entre os diversos países. O medidor está embasado em três dimensões de análise: saúde, educação e renda. De acordo com o United Nations Development Programme (2016), cada dimensão possui uma forma de ser aferida:

i. a saúde é medida através da expectativa de vida, portanto reflete a possibilidade do indivíduo perdurar uma vida longa e saudável;

ii. a educação é mensurada por meio do acesso ao conhecimento e abrange a média de anos escolares de um adulto juntamente com a expectativa de anos escolares que uma criança possui ao ingressar na escola, dessa forma retrata a habilidade de adquirir conhecimento;

iii. a renda corresponde ao padrão de vida dos indivíduos e é medida por meio da Renda Nacional Bruta juntamente com o poder de paridade de compra (que utiliza o dólar de 2005 em seu cálculo) (PNUD, 2016).

O índice tem valores compreendidos entre zero e um, de tal forma que quanto mais próximo da unidade, melhor é o desenvolvimento da região analisada. A despeito das conquistas em mensuração proporcionadas pelo IDH, é importante ressalvar que o fenômeno do desenvolvimento é bastante complexo, de forma que análises quantitativas devem ser complementadas com análises qualitativas.

Nesta perspectiva, cabe mencionar que a grande dispersão entre os valores do IDH revela as desigualdades de oportunidades - relacionadas a saúde, educação, cultura, trabalho etc. - enfrentadas pela população devido ao gênero, identidade, desigualdade salarial e localização. Assim sendo, em 2010 e 2014, surgiram novos medidores do desenvolvimento e que complementam o IDH: o Índice de Pobreza Multidimensional (IPM), IDH Ajustado à Desigualdade (IDHAD), Índice de Desigualdade de Gênero (IDG) e o Índice de Desenvolvimento de Gênero. 
Com a utilização do IDH e de indicadores complementares, expandem-se os horizontes de análise sobre o desenvolvimento, tendo em vista que este - ao passo que analisa as condições socioeconômicas e particularidades da localidade estudada - permite a ampliação de debates relacionados aos problemas sociais e desigualdade enfrentadas pela população. De fato, o relatório Human Development Indices and Indicators: 2018 statistical update informa que tais desigualdades podem levar a consequências indesejadas para a igualdade social e qualidade das instituições políticas, que resultam em um progresso de desenvolvimento humano cada vez menor e mais lento (PNUD, 2018). Portanto, é essencial que tais lacunas sejam preenchidas e que haja a garantia de continuidade do desenvolvimento através das gerações futuras, de forma que estas possuam as mesmas, senão melhores, oportunidades para assegurar o próprio desenvolvimento.

Sob a perspectiva multidimensional do desenvolvimento inspirada em Amartya Sen, cada pessoa é importante e cada existência possui valor, de tal maneira que a cerne do desenvolvimento humano é a universalidade, ou seja, o desenvolvimento é feito por todos e deve ser obtido por todos (PNUD, 2016). Com a Agenda 2030, as nações comprometeram-se a combater a desigualdade, a instabilidade e a insustentabilidade. A seguir, discorre sobre o movimento global em promoção ao desenvolvimento humano sustentável.

\section{Mobilização para o atendimento à agenda 2030 no Brasil}

Em setembro de 2015, líderes mundiais encontram-se na sede da ONU em Nova Iorque e deram origem à Agenda 2030. As orientações da ação multi organismo sinalizariam para os objetivos que deveriam ser perseguidos pelas diferentes nações à luz das diretrizes da sustentabilidade.

Conforme ilustra o Quadro 1, a nova agenda global baseia-se nos 17 Objetivos do Desenvolvimento Sustentável (ODS), que apresentam 169 metas complementares, todas indicando formas de proporcionar melhoria na qualidade de vida das pessoas e do planeta. Os ODS são fruto dos Objetivos de Desenvolvimento do Milênio (ODM), que propunham oito metas internacionais para o desenvolvimento humano, que deveriam ser alcançadas entre os anos 2000-2015.

Djonú et al. (2018) argumentam sobre a importância da execução das ações em direção aos ODS, especialmente nas regiões afetadas pela pobreza e miséria. Para os autores:

Nos países de baixa renda, quase todos os 17 ODS necessitam ser implementados, incluindo os mais básicos - Objetivo 1,

Erradicação da Pobreza, e Objetivo 2, Fome Zero - demonstrando assim um desafio maior do que existente nos demais países.

Afinal, nestes locais, não é apenas o crescimento econômico que possibilitaria a inserção do Desenvolvimento Sustentável, mas uma distribuição de renda com sujeitos donos de seu próprio destino, cientes do seu poder de cidadania e de provocar mudanças. Para tal, outros ODS precisam fazer parte, tais como Objetivo 4 - Educação de Qualidade (DJONÚ et al., 2018, p.3).

Nascimento (2018) destaca que o Brasil se esforçou para alcançar as metas estabelecidas pela Organização das Nações Unidas quando do lançamento dos ODM. Naquela oportunidade, o país obteve relativo êxito, justificado pelo conjunto de estratégias implementadas, com vista a integração e articulação de ações institucionais. Os relatórios de acompanhamento, o incentivo à participação e mobilização social, além do enfoque de políticas públicas contribuíram para o atendimento à quatro ODM (NASCIMENTO, 2018).

Entre as principais metas alcançadas, estão: educação primária para todos, erradicação da fome, redução da incidência do HIV e diminuição da mortalidade infantil. Já entre as metas não alcançadas, estão as ligadas a saneamento e igualdade de gênero. Os ODS configuram-se como uma grande oportunidade de aproveitamento das estratégias mencionadas acima (NASCIMENTO, 2018, p. 4).

Ademais, Silva $(2018$, p. 677) evidencia a importância do governo brasileiro implementar ações que prezam pela "coerência entre seus planos e programas implementados para garantir que as políticas das várias pastas ministeriais se reforcem mutuamente, e não para que entrem em conflito entre si, terminando por prejudicar os esforços para o alcance do desenvolvimento sustentável”. Considerando que há expressiva interdependência entre os diferentes ODS, faz-se indispensável a articulação entre as ações multi organismo. 
Quadro 1 - Grupos técnicos temáticos sobre os ODS e seus respectivos agentes coordenadores

\begin{tabular}{|c|c|}
\hline Grupos técnicos temáticos sobre os ODS & $\begin{array}{c}\text { Agência(s) } \\
\text { Coordenadora(s) }\end{array}$ \\
\hline ODS1. Acabar com a pobreza em todas as suas formas, em todos os lugares & $\begin{array}{l}\text { PNUD e IPC-IG/ } \\
\text { PNUD }^{1}\end{array}$ \\
\hline $\begin{array}{l}\text { ODS2. Acabar com a fome, alcançar a segurança alimentar e melhoria da nutrição e promover a } \\
\text { agricultura sustentável }\end{array}$ & $\mathrm{FAO}^{2}$ \\
\hline ODS3. Assegurar uma vida saudável e promover o bem-estar para todos, em todas as idades & $\begin{array}{l}\mathrm{OPAS}^{\mathrm{OOMS}} \mathrm{OM}^{3} \mathrm{e} \\
\mathrm{UNFPA}^{4}\end{array}$ \\
\hline $\begin{array}{l}\text { ODS4. Assegurar a educação inclusiva e equitativa de qualidade, e promover oportunidades de } \\
\text { aprendizagem ao longo da vida para todos }\end{array}$ & $\mathrm{UNESCO}^{5}$ \\
\hline ODS5. Alcançar a igualdade de gênero e empoderar todas as mulheres e meninas & $\begin{array}{l}\text { ONU Mulheres } \\
\text { UNFPA }\end{array}$ \\
\hline ODS6. Assegurar a disponibilidade e gestão sustentável da água e saneamento para todos & UNESCO \\
\hline $\begin{array}{c}\text { ODS7. Assegurar o acesso confiável, sustentável, moderno e a preço acessível à energia } \\
\text { para todos }\end{array}$ & PNUD \\
\hline $\begin{array}{l}\text { ODS8. Promover o crescimento econômico sustentado, inclusivo e sustentável, emprego } \\
\text { pleno e produtivo e trabalho decente para todos }\end{array}$ & $\mathrm{CEPAL}^{7}$ e $\mathrm{OIT}^{8}$ \\
\hline $\begin{array}{l}\text { ODS9. Construir infraestruturas resilientes, promover a industrialização inclusiva e sustentável e } \\
\text { fomentar a inovação }\end{array}$ & $\mathrm{UNIDO}^{9}$ e UNOPS ${ }^{10}$ \\
\hline ODS10. Reduzir a desigualdade dentro dos países e entre eles & CEPAL \\
\hline $\begin{array}{c}\text { ODS11. Tornar as cidades e os assentamentos humanos inclusivos, seguros, resilientes e } \\
\text { sustentáveis }\end{array}$ & $\begin{array}{l}\text { ONU-HABITAT }^{11} \mathrm{e} \\
\text { UNISDR-CERRD }^{12}\end{array}$ \\
\hline ODS12. Assegurar padrões de produção e de consumo sustentáveis & PNUMA $^{13}$ \\
\hline ODS13. Tomar medidas urgentes para combater a mudança do clima e seus impactos & PNUD E PNUMA \\
\hline $\begin{array}{l}\text { ODS14. Conservar e usar sustentavelmente dos oceanos, dos mares e dos recursos } \\
\text { marinhos para o desenvolvimento sustentável }\end{array}$ & UNESCO \\
\hline $\begin{array}{l}\text { ODS15. Proteger, recuperar e promover o uso sustentável dos ecossistemas terrestres, } \\
\text { gerir de forma sustentável as florestas, combater a desertificação, deter e reverter a } \\
\text { degradação da terra e deter a perda de biodiversidade }\end{array}$ & PNUMA \\
\hline $\begin{array}{l}\text { ODS16. Promover sociedades pacíficas e inclusivas para o desenvolvimento sustentável, } \\
\text { proporcionar o acesso à justiça para todos e construir instituições eficazes, responsáveis e } \\
\text { inclusivas em todos os níveis }\end{array}$ & $\mathrm{UNODC}^{14}$ \\
\hline
\end{tabular}

Fonte: PNUD (2015).

1 Centro Internacional de Políticas para o Crescimento Inclusivo do Programa das Nações Unidas para o Desenvolvimento

2 Organização das Nações Unidas para a Alimentação e a Agricultura

3 Organização Pan-Americana da Saúde/Organização Mundial da Saúde

4 Fundo de População das Nações Unidas

5 Organização das Nações Unidas para a Educação, a Ciência e a Cultura

Entidade das Nações Unidas para a Igualdade de Gênero e o Empoderamento das Mulheres

Comissão Econômica para a América Latina e o Caribe

Organização Internacional do Trabalho

Organização das Nações Unidas para o Desenvolvimento Industrial

0 Escritório das Nações Unidas para Serviços de ProjetoS

11 Programa das Nações Unidas para os Assentamentos Humanos

12 Centro de Excelência para a Redução do Risco de Desastres

13 Programa das Nações Unidas para o Meio Ambiente

14 Escritório das Nações Unidas Sobre Drogas e Crime 
Neste sentido, em 2016, foi criada a Comissão Nacional para os ODS. O órgão tem caráter consultivo e é composto por membros da sociedade civil, além de representantes partidários. Ao todo, são dezesseis membros representantes dos governos federal, estaduais, distrital e municipais e da sociedade civil (SILVA, 2018). Dentre os componentes, pode-se citar: o Conselho Nacional das Populações Extrativistas (CNPE), a União Geral dos Trabalhadores (UGT), a Sociedade Brasileira para o Progresso da Ciência (SBPC), a Associação Nacional de Dirigentes das Instituições Federais do Ensino Superior (Andifes), a Confederação Nacional da Indústria (CNI), o Instituto Ethos de Empresas e Responsabilidade Social (Ethos), a Associação Brasileira de Entidades Estaduais de Meio Ambiente (Abema), a Confederação Nacional de Municípios (CNM), a Secretaria de Governo (Segov-PR), a Casa Civil, os ministérios das Relações Exteriores (MRE), do Meio Ambiente (MMA), do Planejamento, Desenvolvimento e Gestão (MP), do Desenvolvimento Social e Agrário (MDSA), dentre outros (SILVA, 2018).

Em 2017, o Brasil lançou o primeiro Plano de Ação da Comissão Nacional para os ODS, que busca auxiliar as entidades governamentais no processo de concretização da Agenda 2030. O documento previa que, para "não deixar ninguém para trás", tal como expresso na Agenda 2030, os poderes executivo, legislativo e judiciário, assim como o setor produtivo, a academia e as organizações da sociedade civil deverão dar prioridade para a construção de soluções para temas como a promoção de direitos humanos e melhoria das condições sociais e econômicas das populações mais vulneráveis (CNODS, 2017).

Ainda, para que fosse possível colocar em prática os ODS, o Grupo de Trabalho Aberto sobre Objetivos de Desenvolvimento Sustentável (GTA-ODS) definiu quais os principais indicadores sociais, econômicos e ambientais do Brasil que se relacionam com os objetivos e metas do desenvolvimento sustentável. Os ODS foram então divididos entre 16 grupos, responsáveis pela análise de cada particularidade intrínseca ao seu respectivo ODS (PNUD, 2015).

De maneira a acompanhar a superação dos ODS no Brasil, o "Relatório Luz" (documento elaborado pelo Grupo de Trabalho da Sociedade Civil para a Agenda 2030) produz anualmente um conjunto de informações que contempla a evolução da implementação da Agenda 2030. O Relatório Luz 2018 foi publicado no dia 11 de julho de 2018, e analisou 121 dos 169 objetivos propostos pelos ODS em 2015. Porém, o relatório trouxe consigo informações alarmantes, em função dos consecutivos cortes em diversos setores que deveriam ser priorizados para a realização dos ODS.

Com relação ao ODS 1, por exemplo, identifica-se que o Brasil tem encontrado dificuldades em criar condições de perpetuação das conquistas realizadas quando do atendimento aos oito Objetivos do Milênio, principalmente no quesito combate à fome e miséria. A falta de comprometimento do ente estatal e as sucessivas crises econômico-políticas negligenciaram as ações referentes à Agenda 2030. Por conseguinte, nos anos mais recente, foi possível observar o aumento da população pobre e em extrema pobreza.

Outrossim, quanto aos resultados relacionados ao ODS 2 - que trata da fome e agricultura -, a conjuntura também é preocupante. Ressalta-se que as conquistas realizadas até 2015 deram-se por meio de incontáveis esforços direcionados à saúde alimentar das famílias brasileiras, o que ocorreu de fato, através de políticas públicas voltadas à nutrição e segurança alimentar. Contudo, a partir de 2015, presenciou-se uma redução nesses esforços. Em decorrência, há potenciais possibilidades de o Brasil retornar ao mapa da fome da ONU, do qual deixou de fazer parte em 2014.

Diante do cenário ameaçador à integridade, liberdade e qualidade de vida das pessoas, onde há o risco de retorno a condições miseráveis, surge uma esperança que se relaciona a soluções e transformações sociais. Ao combinar o conhecimento científico com o conhecimento adquirido pelas experiências e práticas cotidianas, surgem as Tecnologias Sociais (TS). A próxima seção busca apresentar de que forma as TS contribuem para o desenvolvimento e organização coletiva dos indivíduos visando solucionar problemas relacionados à vulnerabilidade.

\section{Tecnologias sociais potenciais de desenvolvimento e o combate às vulnerabilidades socioeconômicas}

Considerando que o Brasil ocupa posição de destaque quando são avaliados indicadores de desigualdade, pobreza e vulnerabilidade socioeconômica (CAMPELLO et al., 2018), faz-se necessário o debate sobre as estratégias de desenvolvimento passíveis de serem implementadas com vistas à promoção do bem-estar social. Sob tal prisma, as tecnologias surgem como um caminho ao desenvolvimento, pois permitem solucionar problemas produtivos e sócio-técnicos importantes (LANDES, 2005).

Sobretudo, em ambientes onde parcela expressiva da população vive à margem da sociedade, as tecnologias assumem papel preponderante na composição do fenômeno da exclusão social. De acordo com Rutkwoski (2005):

Essa dinâmica econômica baseia-se em intenso processo de inovação tecnológica, o qual reduz cada vez mais os ciclos de vida e aumenta a diversidade dos produtos, e, ao mesmo tempo, reduz as oportunidades de inserção grupos sociais, cujas características socioeconômicas e culturais não correspondam às condições exigidas por esses novos padrões de produção e de consumo. Tal complexidade tecnológica transforma, assim, a tecnologia em vetor de exclusão social (RUTKOWSKI, 2005, p. 181). 
Neste sentido, cabe compreender a definição de tecnologia, sendo "ciência ou teoria da técnica" que, por sua vez, pode ser definida como "o conjunto de processos mecânicos e intelectuais pelos quais os homens atuam na produção" (SANDRONI, 1999, p. 593). Outrossim, as tecnologias podem ser divididas entre a) aquelas que servem ao modelo de extração da mais valia e, portanto, à concentração e riquezas, chamam de Tecnologia Convencional (TC) e b) enquanto aquelas que servem à inclusão social e resolução de problemas sociais chamam de TS, conforme Dagnino (2004) e Rutkowski (2005).

Analogamente, Tecnologia Social pode ser definida como um processo de inovação a ser levado a cabo, coletiva e participativamente, pelos atores interessados na construção daquele cenário desejável. A TS também se aproxima do conceito de "inovação social” (DAGNINO; GOMES, 2000) e figura dentre as melhores alternativas para a correção das desigualdades sociais e da pobreza, uma vez que "consideram, respeitam e concedem a devida importância às características e contextos e às dimensões sociais, culturais, ambientais, econômicas e políticas de uma determinada população, comunidade ou região" (RUTKOWSKI, 2005, p. 192).

Cabe destacar que a Tecnologia Social ocorre, primordialmente, por conta da existência da Economia Solidária e das iniciativas em Economia Popular. Sob tal prisma, é preciso conhecer o sentido de tais termos. A Economia Popular, nas palavras das autoras Icaza e Tiriba (2009, p. 150), compreende o conjunto de "estratégias populares de trabalho e sobrevivência, entendidas como a arte de criar condições favoráveis para satisfação das necessidades humanas, tanto materiais como imateriais". Sendo assim, a Economia Popular é um meio favorável para o desenvolvimento de processos sociais, que levam à melhoria na qualidade de vida das populações que aderem às suas atividades.

Por conta da adesão à Economia Popular, algumas comunidade constituem a chamada Economia Solidária (ES), aqui entendida como um subgrupo da Economia Popular. A Economia Solidária pode ser denominada como um:

[...] conjunto de experiências coletivas de trabalho, produção, comercialização e crédito, organizadas por princípios solidários e que aparecem sob diversas formas: cooperativas e associação de produtores, empresas autogestionárias, bancos comunitários, clubes de troca e diversas organizações populares e urbanas e rurais (SINGER; SOUZA, 2000, p. 123).

Como um viés da Economia Popular, a Economia Solidária tem por objetivo ser instrumento de melhoria na qualidade de vida da população que tem acesso aos seus programas, por meio de cooperativas e associações, uma vez que ocorrerá geração de renda. Ressalta-se que o desenvolvimento das Tecnologias Sociais se faz mais fértil dentro do nicho da Economia Solidária. Essa situação se faz favorável, pois os princípios orientadores da TS se alinham aos princípios das práticas da Economia Popular e Solidária (EPS), especialmente na tocante à busca de alternativas de inclusão social e construção de uma sociedade mais justa. Pela união de seus princípios, a Economia Solidária e as Tecnologias Sociais têm por objetivo central gerar a inclusão de indivíduos coletivamente e de modo autogestionário. Logo, participam de uma dimensão de análise mais ampla de inovações sociais.

De todo modo, a TS busca fomentar meios de produção produtivos sem a presença de segmentação, alienação ou hierarquização dos processos produtivos, mas que, ao contrário, permita o controle direto dos trabalhadores/ trabalhadores e de todos os envolvidos no processo. Além disso, utiliza-se da potencialidade dos produtores/trabalhadores, de maneira a ser controlada pelos próprios produtores, que são - ao mesmo tempo - os trabalhadores e proprietários dos meios de produção (DAGNINO, 2004).

Portanto, as Tecnologias Sociais focam na promoção da inclusão social e pautam um modelo que não contribui para os objetivos de maximização de lucros, mas sim para dimensões humanas, sociais e ambientais em primeiro plano. De modo corroborativo, conforme a Fundação Banco do Brasil (FBB, 2019), a Tecnologia Social alia o "saber popular, organização social e conhecimento técnico-científico" para a solução de problemas sociais, por conseguinte, são alternativas "efetivas e reaplicáveis, propiciando desenvolvimento social em escala". Para Maciel e Fernandes (2011, p. 151):

[...] importante frisar que as TS sempre consideram as especificidades das realidades locais e estão diretamente relacionadas aos processos de organização coletiva e democrática e, portanto, acabam representando soluções para a superação de diferentes situações problemáticas de vulnerabilidade e exclusão social, incidindo assim na melhoria das condições de vida daqueles atores envolvidos com a TS.

Os autores também destacam que muitas iniciativas brasileiras vêm contribuindo para a disseminação de tecnologias sociais, especialmente após a criação da Rede de Tecnologias Sociais (RTS). Esclarece-se que a RTS ${ }^{15}$ é uma rede que integra 786 organizações, a incluir entidades não governamentais, centros de pesquisa, cooperativas, empresas, instituições de ensino, sindicatos, entre outros (MACIEL; FERNANDES, 2011).

15 Para a RTS, as tecnologias sociais são “produtos, técnicas ou metodologias reaplicáveis, desenvolvidas na interação com a comunidade e que representem efetivas soluções de transformação social” (RTS, 2007, p. 28). 
Das experiências em aplicação e desenvolvimento de tecnologias sociais comunicadas pela RTS no Brasil, pode-se citar aquelas vinculadas à resolução de problemas produtivos, sociais e econômicos. O Quadro 2 apresenta algumas das iniciativas e movimentos importantes observados no Brasil ao longo dos últimos anos.

Diante dos Objetivos de Desenvolvimento Sustentável, as Tecnologias Sociais possuem capacidade de assistir àqueles que estão à margem da sociedade. Diante da questão de diminuição da pobreza (e todos suas formas), as EPS ajudam na geração de trabalho e renda, de modo a contribuir com a erradicar a pobreza em suas variáveis dimensões. Ademais, por conta da geração de trabalho e renda, contribui para a ascensão social daqueles que vivem na aba da desigualdade social, ajudando-os a ter maior acesso aos bens e serviços.

Quadro 2 - Tecnologias Sociais disseminadas no Brasil e comunicadas pela RTS

\begin{tabular}{|c|c|}
\hline Tecnologias Sociais & Particularidades \\
\hline Barraginhas & $\begin{array}{c}\text { Consiste na contenção de águas da chuva, por meio de barraginhas sucessivas e } \\
\text { dispersas na propriedade. Evita-se, quando da sua utilização, danos ambientais } \\
\text { como erosões, assoreamentos, poluentes e outros. Aplicação recorrente na região do } \\
\text { cerrado e semiárido brasileiro. }\end{array}$ \\
\hline Banco de Palmas & $\begin{array}{c}\text { Consiste em um banco comunitário organizado pela Associação dos Moradores do } \\
\text { Conjunto Palmeira, localizado em Fortaleza (CE). Trata-se de um sistema econômico } \\
\text { que conta com: a) linhas de microcrédito alternativo; b) instrumentos de incentivo } \\
\text { ao consumo local e c) alternativas de comercialização. A aplicação dessa TS promove } \\
\text { emprego e renda para muitas pessoas na região. }\end{array}$ \\
\hline $\begin{array}{l}\text { Encauchados de vegetais da } \\
\text { Amazônia }\end{array}$ & $\begin{array}{c}\text { Consiste na combinação de técnicas ancestrais de saber indígena e técnicas } \\
\text { modernas para o manuseio do látex nativo. Sua aplicação é amplamente disseminada } \\
\text { nos estados do Pará, Acre, Rondônia e Amazonas. Sobretudo, proporciona condições } \\
\text { para o desenvolvimento local sustentável. }\end{array}$ \\
\hline Central Justa Trama & $\begin{array}{l}\text { Originou a marca da Cadeia Ecológica do Algodão Solidário, ao reunir agricultores } \\
\text { familiares, coletores de sementes, fiadoras, tecedores e costureiras que formam a } \\
\text { Justa Trama. Compreende empreendimentos cobrem todos os elos da indústria têxtil } \\
\text { (do plantio do algodão à roupa) na região Sul do Brasil. }\end{array}$ \\
\hline $\begin{array}{l}\text { Rede Industrial de Confecção } \\
\text { Solidária (RICS) }\end{array}$ & $\begin{array}{c}\text { Compreende grupos de trabalhadoras gaúchas que integram a rede de } \\
\text { empreendimentos autogestionários da RICS. Permitiu a implementação de convênio } \\
\text { entre a Oscip Guayi e o Grupo Hospitalar Conceição de Porto Alegre, para costurar } \\
\text { a linha hospitalar. }\end{array}$ \\
\hline $\begin{array}{l}\text { Produção Agroecológica } \\
\text { Integrada e Sustentável (PAIS) }\end{array}$ & $\begin{array}{c}\text { Modelo circular de agricultura orgânica, com mais de } 6 \text { mil unidades implantadas } \\
\text { ou em fase de implantação. A TS promove a segurança alimentar, aliada à formação } \\
\text { de crianças e jovens, como garantia da subsistência de agricultores e preservação } \\
\text { ambiental. }\end{array}$ \\
\hline
\end{tabular}

Fonte: Adaptado de Maciel e Fernandes (2011, p. 152-153).

Por fim, infere-se que o desenvolvimento humano pode ser gerado por meio da Tecnologia Social, ao passo que é possível criar de trabalho e renda, de modo autogestionário, com o objetivo de erradicar as desigualdades sociais presentes nas sociedades. De modo geral, a TS contribui gerando "soluções para problemas voltados a demandas de alimentação, educação, energia, habitação, renda, recursos hídricos, saúde, meio ambiente, dentre outras” (FBB, 2019).

\section{Considerações finais}

O presente estudo propôs, de maneira geral, debater sobre as estratégias em desenvolvimento humano à luz da implementação de Tecnologias Sociais. Foi possível identificar que o conceito "desenvolvimento humano" foi aprimorado ao longo das últimas décadas, de tal forma que sua abordagem - quando da realização de políticas e ações públicas/privadas - também apresentou transformações expressivas.

Contrariando a ideia geral que se perpetuava de que a riqueza estava diretamente relacionada com o desenvolvimento humano e social, Amartya Sen anunciou a facticidade de a riqueza ser em si um meio para este processo social. Os indivíduos para alcançarem o desenvolvimento, necessitam de qualidade de vida e ampliação de suas 
liberdades, dessa maneira, é possível que os mesmos atinjam sua ampla capacidade de ser. A abordagem do desenvolvimento passa a se afastar do lado monetário e vai ao encontro do lado humano. Por conseguinte, as economias capitalistas expuseram as desigualdades sociais que há muito se perpetuam.

Pobreza, desigualdade de gênero, de renda e identidade são apenas alguns dos exemplos de problemáticas que acometem a atual sociedade. Em função das trajetórias analíticas que enfocavam os aspectos monetários da vida social, tais mazelas foram temporariamente mascaradas pelos instrumentos de ação política. Contudo, novas formas de estudo que abrangem educação, saúde e renda (de maneira multidimensional) tornaram-se possíveis, o que também permite realizar estratégias mais eficientes de combate aos referidos problemas. Sobretudo, destacam-se os meios cooperativos, locais e autogestionários.

Buscando a superação das vulnerabilidades socioeconômicas, a Agenda 2030 surge de um esforço para guiar a cooperação entre entidades. Conectada aos ODS, as metas propostas pela Agenda 2030 buscam o desenvolvimento humano aliado à sustentabilidade do planeta. Ainda, a partir do Plano de Ação da Comissão Nacional para os ODS, o Brasil busca guiar entidades para facilitar o cumprimento de tais metas.

Frente ao processo de realização dos ODS, as Tecnologias Sociais apresentam possíveis e viáveis alternativas para a obtenção do desenvolvimento socioeconômico, especialmente para as classes marginalizadas e vulneráveis. Algumas das TS identificadas no presente estudo, tais como as barraginhas, o Banco de Palmas e RICS, contribuem para a melhoria e assistência da comunidade em que se encontram, através da geração de trabalho, renda, oferta de bens e serviços. Entretanto, é importante destacar que as TS apresentam particularidades em função de seus lócus de aplicação, sendo necessárias adaptações para seu emprego em outros espaços e realidades. Logo, valem as pesquisas que possam identificar interfaces de aproximação e replicação de TS frente aos mais variados problemas sociais.

\section{Referências}

BUSS, P. M. Globalização, pobreza e saúde. Ciência \& Saúde Coletiva, v. 12, n. 6, p. 1575-1589, 2007.

CAMPELlO, T.; GENTIL, P.; RODRIGUES, M.; HOEWELL, G. R. Faces da desigualdade no Brasil: um olhar sobre os que ficam para trás. Saúde debate, v. 42, número especial, p. 54-66, 2018.

CEPAL, Comissão Econômica para a América Latina e o Caribe. Panorama Social de América Latina, 2018. Disponível em: <https://repositorio.cepal.org/handle/11362/44412>. Acesso em: 31 jul. 2019.

CNODS, Comissão Nacional Para os ODS. Plano de Ação 2017 - 2019. Brasília, CNODS, 2017. Disponível em: <http:// www.itamaraty.gov.br/images/ed_desenvsust/Plano-Acao-ComissaoNacional-ODS.pdf>. Acesso em: 14 ago. 2019.

DAGNINO, R; BRANDÃO, F. C.; NOVAES, H. T. Sobre o marco analítico conceitual da tecnologia social. In: Tecnologia social: uma estratégia para o desenvolvimento. Fundação BB: RJ, 2004.

DAGNINO, R.; GOMES, E. Sistema de inovação social para prefeituras. In: Conferência Nacional de Ciência e Tecnologia para Inovação. Anais. São Paulo, 2000.

DJONU, P.; RABELO, A. S.; LIMA, P. V. P. S.; SOUTO, M. V. S.; SABADIA, J. A. B.; SUCUPIRA JUNIOR, P. R. G. Objetivos do Desenvolvimento Sustentável e Condições de Saúde em Áreas de Risco. Ambiente \& Sociedade, v. 21, p. 1-20, 2018.

DUPAS, G. A lógica da economia global e a exclusão social. Estudos Avançados, v. 12, n. 34, p. 121-159, 1998.

FBB, Fundação Banco do Brasil. Tecnologia Social. Disponível em: http://tecnologiasocial.fbb.org.br/ tecnologiasocial/o-que-e/tecnologia-social/o-que-etecnologia-social.htm. Acesso em: 07 ago. 2019.

ICAZA, A. M. S.; TIRIBA, L. Economia Popular. In: CATTANI, A. D., et al. Dicionário Internacional da Outra Economia. São Paulo: Almedina, 2009.

IPEA, Instituto de Pesquisa Econômica Aplicada. ODS - Metas Nacionais dos Objetivos de Desenvolvimento Sustentável, 2018. Disponível em: <http://www.ipea.gov.br/portal/images/stories/PDFs/livros/livros/180801_ods_ metas_nac_dos_obj_de_desenv_susten_propos_de_adequa.pdf>. Acesso em: 31 jul. 2019.

JOLLY, R. Human development and neo-liberalism: Paradigms compared. In: SAKIKO FUKUDA-PARR AND 
A.K. SHIVA KUMAR (eds). Readings in Human Development. Oxford: New Delhi, 2003.

LANDES, D. S. Prometeu desacorrentado: transformação tecnológica e desenvolvimento industrial na Europa ocidental, desde 1750 até nossa época. Rio de Janeiro/RJ: Elsevier, 2005. 627p.

MACIEL, A. L. S.; FERNANDES, R. M. C. Tecnologias sociais: interface com as políticas públicas e o Serviço Social. Serv. Soc. Soc., n. 105, p. 146-165, 2011.

NASCIMENTO, .F. R. F. BrasilODS: um modelo colaborativo de apoio à realização dos objetivos de desenvolvimento sustentável da ONU. Rio de Janeiro: UFRJ/COPPE, 2018. ONU, Organização das Nações Unidas Brasil. PNUD: Programa das Nações Unidas para o Desenvolvimento. Disponível em: < https:// nacoesunidas.org/agencia/pnud/ > Acesso em 31 de julho de 2019.

PNUD, Programa das Nações Unidas para o Desenvolvimento. Acompanhando a agenda 2030 para o desenvolvimento sustentável: subsídios iniciais do Sistema das Nações Unidas no Brasil sobre a identificação de indicadores nacionais referentes aos objetivos de desenvolvimento sustentável/Programa das Nações Unidas para o Desenvolvimento. Brasília: PNUD, 2015.

PNUD, Programa das Nações Unidas para o Desenvolvimento; IPEA, Instituto de Pesquisa Econômica e Aplicada; FJP, Fundação João Pinheiro. O que é idh. Disponível em: < http://www.br.undp.org/content/brazil/pt/ home/idh0/conceitos/o-que-e-o-idh.html>. Acesso em 07 ago. 2019.

PNUD, United Nations Development Programme. About Human Development, 2019. Disponível em: <http:// www.hdr.undp.org/en/humandev>. Acesso em 07 ago. 2019.

PNUD, United Nations Development Programme. Human Development Report 2016: Human Development for Everyone. Nova Iorque: ONU, 2016.

PNUD, United Nations Development Programme. Human Development Indices and Indicators: 2018 statistical update. Nova Iorque: ONU, 2018.

RTS, Rede de Tecnologia Social. Tecnologia social: conceito. Brasília: RTS, 2009.

RUTKOWSKI, J. E. Rede de Tecnologias Sociais: pode a tecnologia proporcionar desenvolvimento social? In: LIANZA, S.; ADDOR, F (org). Tecnologia e desenvolvimento social e solidário. Porto Alegre/RS: Editora UFRGS, 2005.

SANDRONI, P. (org.). Novíssimo dicionário de economia. São Paulo: Best Seller, 1999.

SEN, A. Desenvolvimento como liberdade. São Paulo: Companhia das Letras, 2010.

SILVA, E. R. A. Os Objetivos Do Desenvolvimento Sustentável e os Desafios da Nação. In: NEGRI, J. A.; ARAUjO, B. C.; BACELETTE, R. Desafios da nação: artigos de apoio. Brasília: Ipea, 2018.

SINGER, P. Economia Solidária: um modelo de produção e distribuição. In: SINGER, P.; SOUZA, A.R. (Org.). A Economia Solidária no Brasil: a autogestão como resposta ao desemprego. São Paulo. Contexto, 2000.

SINGER, P. Desenvolvimento capitalista e desenvolvimento solidário. Estudos Avançados, v. 18, n. 51, p. 7-22, 2004.

\section{Agradecimentos}

Os autores agradecem o apoio do Conselho Nacional de Desenvolvimento Científico e Tecnológico (CNPq) e da Coordenação de Aperfeiçoamento de Pessoal de Nível Superior (Capes) pelo auxílio financeiro para a execução da pesquisa. Em especial, à Chamada CNPq/MCTIC/MDS № 36/2018 - C - Avaliação de Tecnologia Social e ao Programa Especial de Difusão e Popularização da Ciência e Tecnologia. 